\title{
Multifocal Electroretinography in Diabetic Patients without Retinopathy
}

\author{
Ozgur Balta, ${ }^{1}$ (i) Gulten Sungur, ${ }^{2}$ () Mehmet Yakin, ${ }^{2}$ () Nurten Unlu, ${ }^{2}$ (b) Oyku Bezen Balta, ${ }^{3}$ \\ Eyup Ozcan, ${ }^{4}$ (i) Firdevs Ornek ${ }^{2}$
}

${ }^{1}$ Department of Ophthalmology, Dr. Nafiz Korez Sincan State Hospital, Ankara, Turkey

2Department of Ophthalmology, Ankara Training and Research Hospital, Ankara, Turkey

${ }^{3}$ Department of Family Medicine, Yildirim Beyazit University Faculty of Medicine, Ankara, Turkey

${ }^{4}$ Department of Ophthalmology, Private Goznuru Eye Hospital, Gaziantep, Turkey

\begin{abstract}
Objectives: This study aimed to assess the multifocal electroretinography (mfERG) findings in diabetic patients without retinopathy according to the $\mathrm{HbAlc}$ levels and diabetes duration.

Methods: A total of 62 eligible patients with Type 2 diabetes mellitus and 30 healthy controls which were matched by age and sex were included in the study. Only the right eye of each patient was analyzed. All of the participants underwent a comprehensive ophthalmic examination, and the mfERG responses which were NI-PI amplitude, NI implicit times and PI implicit times were calculated.

Results: The mfERG NI-PI amplitude was significantly reduced in diabetic patients compared to controls in inner two rings. There was significant different between controls and stable patients' mfERG PI implicit times in ring 2 . It was found that there were negative correlation trends between diabetes duration and mfERG NI-PI amplitude, there were negative, positive correlation trends between diabetes duration and $\mathrm{NI}$ implicit times and PI implicit times in all rings. There was a statistically significant negative correlation between diabetes duration and NI-PI amplitude only in ring 5. Furthermore, it was found that there were statistically significant positive correlations between diabetes duration and NI implicit times in ring I, 2 and 5. There was a significant correlation between diabetes duration and PI implicit times only in ring 2.

Conclusion: We demonstrated that mfERG NI-PI amplitude was reduced in inner retinal areas (ring I and ring 2), and $\mathrm{PI}$ implicit time was delayed only in ring 2 in Turkish diabetic patients without retinopathy. There was a statistically significant correlation between diabetes duration and NI-PI amplitude and NI implicit times in some retinal areas.
\end{abstract}

Keywords: Diabetes, diabetic retinopathy, multifocal electroretinography.

\section{Introduction}

In 2012, there were approximately 93 million people with diabetic retinopathy (DR), 17 million with proliferative DR, 21 million with diabetic macular edema, and 28 million with vision-threatening DR worldwide (I). DR was the fifth most common cause of preventable blindness and fifth most common cause of moderate-severe visual impairment (MSVI) be- tween 1990 and 2010. Furthermore, the age-standardized prevalence of DR causing MSVI had increased slightly from 1990 to 2010 (2).

Electroretinography (ERG) is an objective method of evaluating the retinal function and also demonstrates abnormal results in diabetic patients without any ophthalmoscopic findings (3). The multifocal ERG (mfERG) enables assessment of many retinal areas within roughly $8 \mathrm{~min}$ per eye (4).

Address for correspondence: Ozgur Balta, MD. Nafiz Korez Sincan Devlet Hastanesi, Oftalmoloji Anabilim Dalı, Ankara, Turkey

Phone: +905530619572 E-mail: drozgurbalta@hotmail.com

Submitted Date: March 26, 2018 Accepted Date: October 02, 2018 Available Online Date: December 19, 2018

${ }^{\odot}$ Copyright 2018 by Beyoglu Eye Training and Research Hospital - Available online at www.beyoglueye.com 
Palmowski et al. (5) found that in patients with diabetes mfERG amplitudes were reduced and implicit times were increased compared to healthy peoples. Harrison et al. found that mfERG implicit time is a good predictor of DR onset in patients with diabetes without DR (6). The ability of the mfERG findings to predict the future retinopathy provides clinicians a good tool to screen, follow-up, and even consider early prophylactic treatment of the patients with DR (7).

As shown by many studies, preventing elevated blood glucose significantly reduces the risk of ocular and visual complications of diabetes (8-II). Kahn and Bradley found a strong positive association between retinopathy and duration of diabetes in a random sample of 9/4 diabetic patients (12). Among younger-onset patients with diabetes, the prevalence of any retinopathy was $8 \%$ at first 3 years, $25 \%$ at 5 years, $60 \%$ at 10 years, and $80 \%$ at 15 years. The prevalence of proliferative DR was $0 \%$ at first 3 years and increased to $25 \%$ at 15 years. The 4 -year incidence of developing proliferative retinopathy in the younger-onset group increased from $0 \%$ during the first 5 years to $27.9 \%$ during years 13-14 of diabetes (13).

The aims of this study were to compare mfERG findings (NI-PI amplitude and PI-implicit time) in diabetic patients without DR who had different HbAlc levels to healthy control participants without diabetes and to assess the correlation $\mathrm{mfERG}$ responses with diabetes duration.

\section{Methods}

\section{Study Population and Ethical Considerations}

This prospective study was performed in the Departments of Ophthalmology at Ankara Training and Research Hospital, Turkey. This study was approved by the Institutional Review Board. Informed consents were obtained from all patients and tenets of the Declaration of Helsinki were followed.

A total of 62 eligible patients with Type 2 diabetes mellitus and 30 age- and sex-matched healthy controls were included in the study. The diagnosis of Type II diabetes mellitus was based on criteria of the World Health Organization (WHO). Exclusion criteria included best-corrected visual acuity (BCVA) worse than 20/20, high spherical or cylindrical $> \pm$ I diopter refractive errors, pseudoexfoliation syndrome, DR, history of uveitis, gluacoma, ocular trauma, previous intraocular surgery, and presence of systemic diseases, such as renal or hepatic dysfunction, obesity, and rheumatological diseases. Furthermore, people who were currently smoking or using alcohol, and/or had prosthetic devices or electromagnetic field generating devices, were excluded in the study.

Age, sex, duration of diabetes, and $\mathrm{HbAlc}$ levels were recorded. Diabetic patients were classified into two groups by $\mathrm{HbAlc}$ levels. Patients with $7 \%$ or less $\mathrm{HbAlc}$ levels were grouped as a stable patient group, patients with $>7 \%$ were grouped unstable patient group. Furthermore, only the right eye of each patient was analyzed.

All of the patients underwent a comprehensive ophthalmic examination, including medical history review, refraction, BCVA, and intraocular pressure measured by Goldmann applanation tonometer, anterior, and fundus segment examinations.

\section{Multifocal ERG}

Retiscan Retipor 32 TM (Roland Consult, Wiesbaden, Germany) was used for recording according to the International Society for Clinical Electrophysiology of Vision standards (20I I edition) (14). After the anesthetizing with topical $0.5 \%$ proparacaine hydrochloride, the active electrodes (ERG-Jet Universo, Switzerland) were placed on the cornea following pulling up the upper eye limb. The neuter of the reference electrodes was placed at the frontal region; the other one was positioned to $2 \mathrm{~cm}$ lateral of the external canthal region, with plaster after the concave inner surfaces were filled with 2-3\% methylcellulose.

The local retinal sensitivity changes were observed in the 61 points from the totally $60^{\circ}$ field which were $30^{\circ}$ on either side of the fixation point after the case was positioned $24 \mathrm{~cm}$ away from the screen. The test was applied after the pupils were dilated with $1 \%$ tropicamide and $2.5 \%$ phenylephrine, and the participants were standing in room light for $15 \mathrm{~min}$. The stimuli were presented on a 20 -inch monitor (Sony Multiscan G520 TM, Japan), driven at a $60-\mathrm{Hz}$ frame rate and consisted of an array of $6 \mathrm{I}$ hexagonal elements, according to binary $\mathrm{m}$-sequence with a base interval of $13.3 \mathrm{~ms}$. White hexagons had a luminance of $120 \mathrm{~cd} / \mathrm{m}^{2}$, and dark hexagons were $\mathrm{Icd} / \mathrm{m}^{2}$ in local contrasts of $99 \%$. Signals were amplified 100.000 times and filtered with a range of $10-100 \mathrm{~Hz}$ and recorded with a sampling interval of $83 \mathrm{~ms}$ ( 16 times per video frame) under fixation control. In the presence of the conditions that caused the degradation of the signals such as blinking of patients and loss of fixation, the recording was repeated. The averages of the first-order kernel mfERG amplitudes and latancies were calculated for each five concentric rings. The retinal areas of rings were ring 1 (central-2. $1^{\circ}$ ), ring $2\left(1.4^{\circ}-6.7^{\circ}\right)$, ring $3\left(5.7^{\circ}-12.0^{\circ}\right)$ ring $4\left(9.5^{\circ}-19.8^{\circ}\right)$, and ring $5\left(15.1^{\circ}-28.5^{\circ}\right)$.

\section{Statistical Analysis}

Statistical analyzes were performed with the Statistica version 10 (StatSoft Inc.). Descriptive statistics (median, minimum, maximum, and frequencies) were used to describe the baseline characteristics of the study groups. Kruskal-Wallis test was used to compare non-normally distributed quantitative variables between the study groups. Multiple com- 
parisons of mean ranks for all groups were carried out as post hoc test, and Bonferroni adjustment was used for $P$ values. To compare qualitative variables, the Pearson Chisquare test was used. The association of diabetes duration with mfERG NI-PI amplitude, NI implicit times and PI implicit times were analyzed by Spearman correlation test in diabetes patients.

\section{Results}

Out of 30 control participants $18(60.0 \%)$, out of 30 stable patients $18(60.0 \%)$ and out of 32 unstable $(62.5)$ were male. The mean age of controls was $49.4 \pm 4.7$, stable patient group was $51.9 \pm 4.8$, and unstable patient group was $49.7 \pm 7.6$. The gender $(p=0.987)$ and age $(p=0.314)$ were not statistically different between study groups (Table I).

In-ring I, the mfERG NI-PI amplitude was significantly reduced in stable and unstable patients compared to controls $(0.0003)$. In post hoc analysis, it was found that there was a statistically significant difference between controls and stable patients $(p=0.005 \mathrm{I})$, and unstable patients $(p=0.0004)$. In-ring 2 , there were also statistically significant differences between controls and patient groups $(p=0.0267)$. In post hoc test, while there was no significantly significant difference between controls and stable patients $(p=0.1683)$, and there was a statistically significant difference between controls and unstable patients $(p=0.0265)$ in ring 2 . The mfERG NI-PI amplitude findings of controls and patient groups were statistically similar in rings 3,4 , and 5 . In post hoc anal$y$ sis, there was no statistically significant difference between two patient groups in all rings (post hoc test results were not shown) (Table 2).

It was found that there were no statistically significant differences in the mfERG PI implicit times findings between controls and patient groups in rings I, 3, 4, and 5. However, there was a significantly significant difference between groups in ring $2(p=0.0138)$. In post hoc analysis, while there was significantly significant difference between controls and stable patients $(p=0.0169)$, and there was no statistically significant difference between controls and unstable patients $(p=0.1913)$ in ring 2 (post hoc test results were not shown) (Table 3).

In an analysis of the mfERG NI implicit times, it was found that there were no statistically significant differences between controls and patient groups in all rings I, 2, 3, 4, and 5 (Table 4).

Although it was found that there were negative correlation trends between diabetes duration and mfERG NI-PI amplitude, there were positive correlation trends between

Table I. Baseline characteristics of the study group

\begin{tabular}{|c|c|c|c|c|}
\hline & Controls $(n=30)$ & Stable patients $(n=30)$ & Unstable patients $(n=32)$ & $\mathbf{p}$ \\
\hline \multicolumn{5}{|l|}{ Gender } \\
\hline Male (\%) & $18(60.0)$ & $18(60.0)$ & $20(62.5)$ & $* 0.987$ \\
\hline \multicolumn{5}{|l|}{ Age (years) } \\
\hline Mean $\pm S D$ & $49.4 \pm 4.7$ & $51.9 \pm 4.8$ & $49.7 \pm 7.6$ & $* * 0.314$ \\
\hline Minimum & 42.0 & 42.0 & 40.0 & \\
\hline Maximum & 60.0 & 59.0 & 60.0 & \\
\hline
\end{tabular}

*Chi-square test was used; **Kruskal-Wallis test was used; SD: Standard deviation.

Table 2. Median, minimum and maximum NI-PI amplitude $\left(\mathrm{nV} / \mathrm{deg}^{2}\right)$ for 5 rings of retina

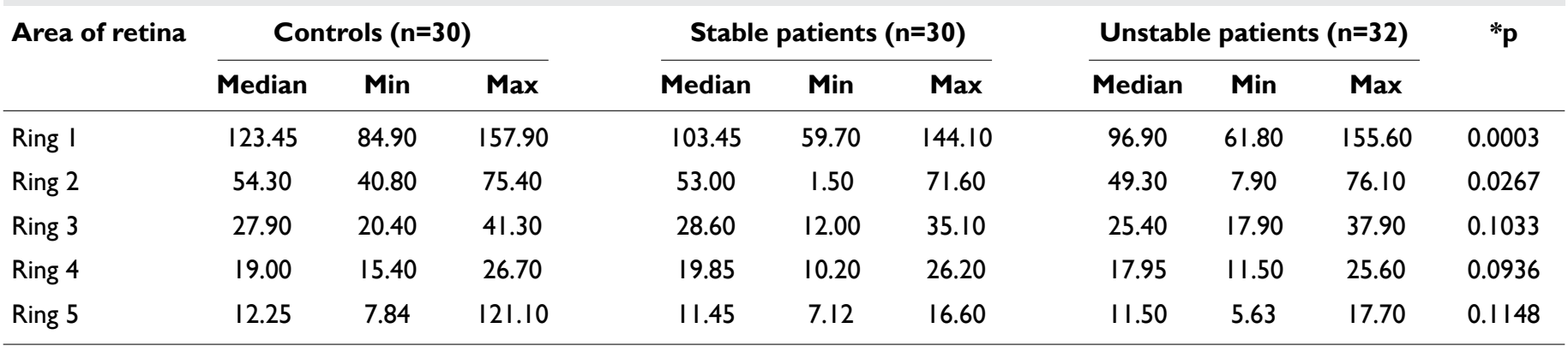

*Kruskal-Wallis test was used. 
Table 3. Median, minimum and maximum PI implicit times (ms) for 5 rings of retina

\begin{tabular}{|c|c|c|c|c|c|c|c|c|c|c|}
\hline Area of retina & \multicolumn{3}{|c|}{ Controls $(n=30)$} & \multicolumn{3}{|c|}{ Stable patients $(n=30)$} & \multicolumn{3}{|c|}{ Unstable patients $(n=32)$} & $* p$ \\
\hline Ring I & 35.80 & 33.80 & 38.80 & 35.80 & 33.90 & 39.80 & 35.80 & 31.90 & 41.80 & 0.1161 \\
\hline Ring 2 & 31.90 & 3.90 & 32.90 & 32.40 & 30.90 & 37.80 & 31.90 & 9.00 & 35.80 & 0.0138 \\
\hline Ring 3 & 31.40 & 29.90 & 33.90 & 31.90 & 30.90 & 34.80 & 31.90 & 29.90 & 35.80 & 0.0521 \\
\hline
\end{tabular}

*Kruskal-Wallis test was used.

Table 4. Median, minimum and maximum NI implicit times (ms) for 5 rings of retina

\begin{tabular}{|c|c|c|c|c|c|c|c|c|c|c|}
\hline \multirow[t]{2}{*}{ Area of retina } & \multicolumn{3}{|c|}{ Controls $(n=30)$} & \multicolumn{3}{|c|}{ Stable patients $(n=30)$} & \multicolumn{3}{|c|}{ Unstable patients $(n=32)$} & \multirow[t]{2}{*}{$* \mathbf{p}$} \\
\hline & Median & Min & $\operatorname{Max}$ & Median & Min & $\operatorname{Max}$ & Median & Min & $\operatorname{Max}$ & \\
\hline Ring I & 16.90 & 12.90 & 149.00 & 16.90 & 14.90 & 20.90 & 16.90 & 13.90 & 22.90 & 0.3446 \\
\hline Ring 2 & 14.90 & 12.90 & 16.90 & 14.90 & 13.90 & 16.90 & 14.90 & 12.90 & 17.90 & 0.1203 \\
\hline Ring 3 & 14.90 & 12.90 & 16.90 & 14.90 & 13.90 & 17.90 & 14.90 & 12.90 & 17.90 & 0.0895 \\
\hline Ring 4 & 15.40 & 12.90 & 17.90 & 15.40 & 14.90 & 18.90 & 15.90 & 12.90 & 19.90 & 0.4047 \\
\hline Ring 5 & 16.90 & 13.90 & 18.90 & 16.90 & 15.90 & 18.90 & 16.40 & 14.90 & 19.90 & 0.1123 \\
\hline
\end{tabular}

*Kruskal-Wallis test was used.

Table 5. The correlation of diabetes duration with mfERG NI-PI amplitude, NI implicit times and PI implicit times

\begin{tabular}{|c|c|c|c|c|c|c|}
\hline \multirow[t]{2}{*}{ Area of retina } & \multicolumn{2}{|c|}{$\begin{array}{c}\text { Diabetes duration with } \\
\text { NI-PI amplitude }\end{array}$} & \multicolumn{2}{|c|}{$\begin{array}{l}\text { Diabetes duration with } \\
\text { NI implicit times }\end{array}$} & \multicolumn{2}{|c|}{$\begin{array}{l}\text { Diabetes duration with } \\
\text { PI implicit times }\end{array}$} \\
\hline & $\begin{array}{c}\text { Correlation } \\
\text { Coefficient }(\mathbf{R})\end{array}$ & $* p$ & $\begin{array}{c}\text { Correlation } \\
\text { Coefficient (R) }\end{array}$ & $* p$ & $\begin{array}{c}\text { Correlation } \\
\text { Coefficient (R) }\end{array}$ & $* p$ \\
\hline Ring I & -0.127 & 0.342 & 0.287 & 0.029 & 0.249 & 0.059 \\
\hline Ring 2 & -0.207 & 0.118 & 0.438 & 0.001 & 0.342 & 0.009 \\
\hline Ring 4 & -0.196 & 0.140 & 0.221 & 0.096 & 0.186 & 0.162 \\
\hline Ring 5 & -0.317 & 0.015 & 0.270 & 0.040 & 0.172 & 0.197 \\
\hline
\end{tabular}

*Spearman Correlation test was used; mfERG: Multifocal electroretinography.

diabetes duration and $\mathrm{NI}$ implicit times and PI implicit times in all rings (Fig. I). There was a statistically significant negative correlation between diabetes duration and NI-PI amplitude in ring $5(r=-0.317, p=0.015)$, but not significant correlation in other rings. Furthermore, it was found that there were statistically significant positive correlations between diabetes duration and $\mathrm{NI}$ implicit times in ring I, 2, and 5 , but not in ring 3 and 4 .

While there were not statistically significant correlations between diabetes duration and PI implicit times in ring I, 3,
4 , and 5 , there was significant correlation between diabetes duration and $\mathrm{PI}$ implicit times only in ring 2 (Table 5).

\section{Discussion}

The WHO estimates that, globally, 422 million people aged over 18 years were living with diabetes in 2014. In 2012, there were 1.5 million deaths worldwide directly caused by diabetes, and it was the eighth leading cause of death (15). DR was the cause of MSVI in $1.9 \%$ and of blindness in $2.6 \%$ globally in 2010 (2). Good metabolic control significantly re- 

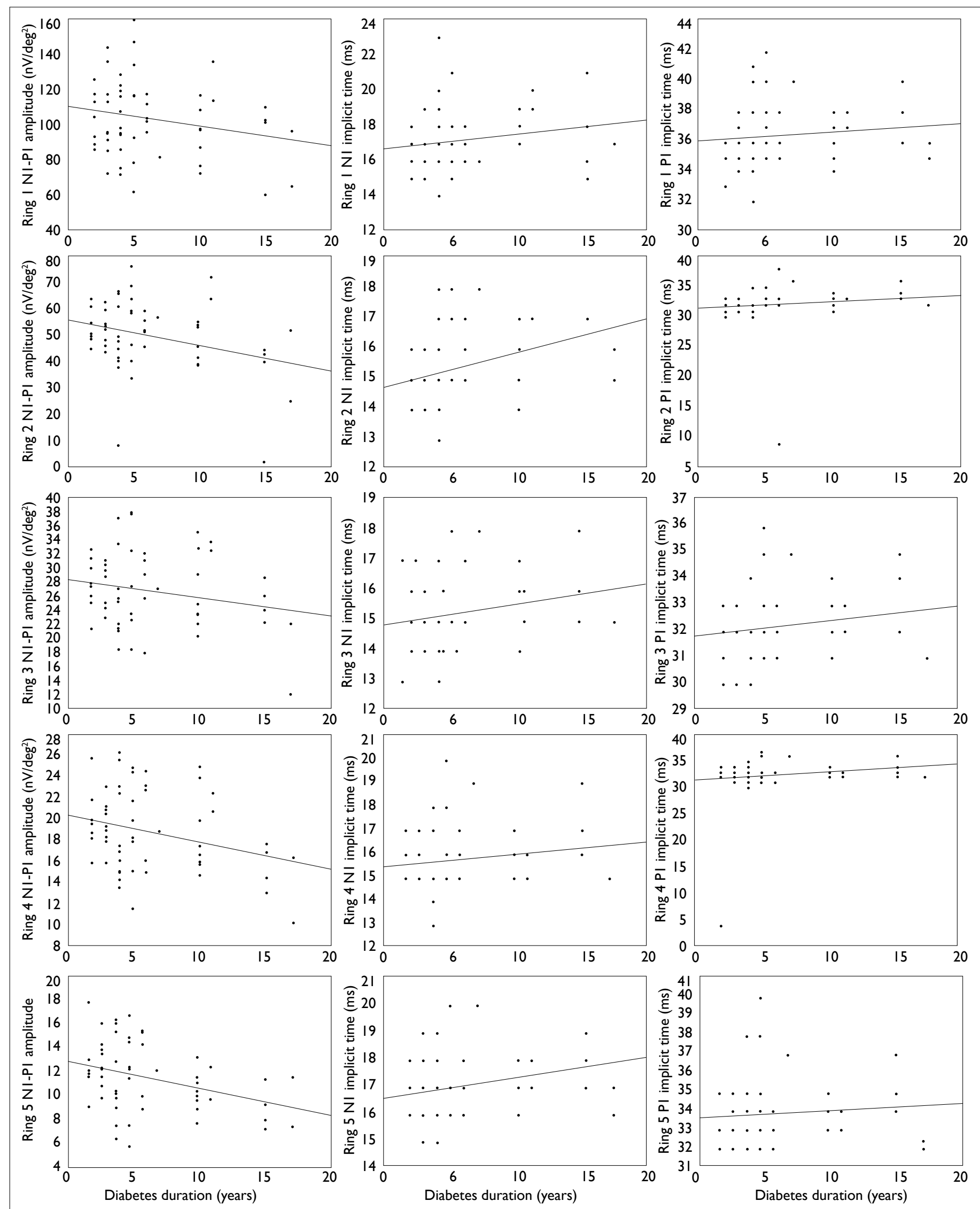

Figure I. Correlation of NI-PI amplitude, NI implicit time, PI implicit time and diabetes duration. 
duces the risk of development and progression of ocular and visual complications of both Type I and Type 2 diabetes (9).

Bearse and Sutter reported that abnormal mfERG implicit times are locally predictive of the development of new DR over I and 2 years, and these functional abnormalities are spatially associated with retinopathy once it is present. They said that retinal dysfunction in early DR is primarily due to neuropathy or neuro vasculopathy rather than microvascular pathology alone (7).

It is complicated whether sex/gender itself or other related risk factors cause the male and female differences in diabetes and DR. Therewithal, sex/gender is a variable that must be considered inaccurate viewpoints of diabetes and $D R$ in any case of etiology $(16,17)$. There is a huge literature about age's effect on diabetes. Namperumalsamy et al. reported that older age ( $>50$ years) was a significant risk factor for the prevalence of DR in a South Indian community (18). The Wisconsin epidemiological study of DR reported that severity of retinopathy was related to younger age at diagnosis, and the 10-year incidence of retinopathy and progression of retinopathy were highest in the group disease onset before 30 years $(19,20)$. In this study, sex and age were statistically similar between study groups. This situation made the evaluation of the study results convenient.

We found that mfERG NI-PI amplitude was reduced in inner retinal areas (ring $I$ and ring 2 ) in diabetic patients compared to controls. Furthermore, we found that PI implicit time was delayed only in ring 2 , and $\mathrm{NI}$ implicit time was similar in the diabetic patient group which had different $\mathrm{HbAlc}$ levels compared to the control group. There was a statistically significant negative correlation between diabetes duration and NI-PI amplitude only in ring 5. Furthermore, it was found that there were statistically significant positive correlations between diabetes duration and $\mathrm{NI}$ implicit times in ring I, 2, and 5 , and there was significant correlation between diabetes duration and PI implicit times only in ring 2 .

Adhikari et al. (2I) demonstrated reduced mfERG NI-PI amplitude and delayed PI-implicit time in Nepalese diabetic patients without retinopathy. They found that diabetes duration and fasting blood glucose have a significant influence on implicit time, but not on amplitude.

Han et al. (22) studied mfERG responses to predict the development of DR with 22 patients which II are diabetic patients with nonproliferative DR (NPDR), and II are diabetic patients without retinopathy. They retested patients 12 months after the first examination. They found that new retinopathy developed in 7 of the eyes with NPDR, and the eyes without retinopathy did not develop new retinopathy after I year. Furthermore, they reported that mfERG implicit times were more delayed in NPDR eyes, but not in eyes without retinopathy and control eyes, and mfERG am- plitudes had no predictive power.

Dhamdhere et al. (23) found that Type 2 diabetes patients had reduced mfERG amplitude and longer PI implicit time than the controls and Type I diabetes patients in their trial which was studied 45 diabetic patients without retinopathy ( 10 with Type I and 35 with Type 2 diabetes).

In a 78 eyes included study to predict local formation of $D R$ in diabetic patients without retinopathy, it was reported that multivariate analysis (mfERG implicit time Z-score, sex, diabetes duration, blood glucose, $\mathrm{HbAlc}$, age, and diabetes type) showed mfERG implicit time to be predictive for DR development in a zone after adjusting for diabetes type, with a sensitivity of $80 \%$ and a specificity of $74 \%(6)$.

Laron et al. (24) reported that mean mfERG implicit time was significantly longer in the patients compared with controls, but amplitude was similar, in their study which they evaluate associations between mfERG responses in II 5 Type I diabetic adolescents without retinopathy compared to 30 controls. They found that implicit time was positively correlatedwith $\mathrm{HbAlc}$ but not correlated with diabetes duration, $B G$, or age.

In a study conducted with 14 Type I diabetic patients without retinopathy and 14 healthy controls, authors found that, during acute normoglycemia, patients demonstrated an overall I.36-ms delay of the PI first-order implicit times $(p=0.0013)$ and a $0.72-\mathrm{ms}$ delay of the second-order PI $(\mathrm{p}=0.0049)$ compared with healthy subjects. They reported that, during acute hyperglycemia, the PI first-order delay was only $0.8 \mathrm{I}$ $m s(p=0.02)$, and the PI second-order implicit time was comparable to that of healthy subjects $(p>0.05)$. The magnitude of the diabetes-associated implicit time delay, at both levels of glycemia, was proportional to the level of chronic hyperglycemia at study entry, as expressed by the patients' HbAlc. They said that the results show that chronic hyperglycemia induces an adaptational response that tends to normalize retinal implicit times at a higher level of habitual glycemia (25).

\section{Conclusion}

We demonstrated that mfERG NI-PI amplitude was reduced in inner retinal areas (ring I and ring 2), and $\mathrm{PI}$ implicit time was delayed only in ring 2 in Turkish diabetic patients without retinopathy. There was a statistically significant negative correlation between diabetes duration and NI-PI amplitude only in ring 5 , and statistically significant positive correlations between diabetes duration and $\mathrm{NI}$ implicit times in some retinal areas. These results may be specific to the study group, so further multicenter and longitudinal studies are required to evaluate different manifestation forms of diabetes.

\section{Disclosures}

Peer-review: Externally peer-reviewed.

Conflict of Interest: None declared. 
Authorship Contributions: Involved in design and conduct of the study (OB, GS, NU, OBB, FO); preparation and review of the study $(\mathrm{OB})$; data collection (OB, GS); and statistical analysis (OB, EO).

\section{References}

I. Yau JW, Rogers SL, Kawasaki R, Lamoureux EL, Kowalski JW, Bek T, et al; Meta-Analysis for Eye Disease (META-EYE) Study Group. Global prevalence and major risk factors of diabetic retinopathy. Diabetes Care 2012;35:556-64.

2. Bourne RR, Stevens GA, White RA, Smith JL, Flaxman SR, Price $\mathrm{H}$, et al; Vision Loss Expert Group. Causes of vision loss worldwide, 1990-2010: a systematic analysis. Lancet Glob Health 2013; I:e339-49.

3. Tzekov R, Arden GB. The electroretinogram in diabetic retinopathy. Surv Ophthalmol 1999;44:53-60.

4. Bearse MA, Sutter EE. Imaging localized retinal dysfunction with the multifocal electroretinogram. J Opt Soc Am A Opt Image Sci Vis 1996; 13:634-40.

5. Palmowski AM, Sutter EE, Bearse MA, Fung W. Mapping of retinal function in diabetic retinopathy using the multifocal electroretinogram. Invest Ophthalmol Vis Sci 1997;38:2586-96.

6. Harrison WW, Bearse MA Jr, Ng JS, Jewell NP, Barez S, Burger $D$, et al. Multifocal electroretinograms predict onset of diabetic retinopathy in adult patients with diabetes. Invest Ophthalmol Vis Sci 20I I;52:772-7.

7. Bearse MA Jr, Adams AJ, Han Y, Schneck ME, Ng J, BronsonCastain $\mathrm{K}$, et al. A multifocal electroretinogram model predicting the development of diabetic retinopathy. Prog Retin Eye Res 2006;25:425-48.

8. Effect of intensive therapy on the development and progression of diabetic nephropathy in the Diabetes Control and Complications Trial. The Diabetes Control and Complications (DCCT) Research Group. Kidney Int 1995;47: I703-20.

9. Stratton IM, Kohner EM, Aldington SJ, Turner RC, Holman RR, Manley SE, et al. UKPDS 50: risk factors for incidence and progression of retinopathy in Type II diabetes over 6 years from diagnosis. Diabetologia 2001;44:156-63.

10. The relationship of glycemic exposure ( $\mathrm{HbAlc}$ ) to the risk of development and progression of retinopathy in the diabetes control and complications trial. Diabetes 1995;44:968-83.

II. Rodriguez-Fontal M, Kerrison JB, Alfaro DV, Jablon EP. Metabolic control and diabetic retinopathy. Curr Diabetes Rev 2009;5:3-7.

12. Kahn HA, Bradley RF. Prevalence of diabetic retinopathy. Age, sex, and duration of diabetes. Br J Ophthalmol 1975;59:345-9.

13. Klein R, Klein BE, Moss SE, Davis MD, DeMets DL. The Wisconsin epidemiologic study of diabetic retinopathy. II. Prevalence and risk of diabetic retinopathy when age at diagnosis is less than 30 years. Arch Ophthalmol 1984;102:520-6.

14. Hood DC, Bach M, Brigell M, Keating D, Kondo M, Lyons JS, Marmor MF, et al; International Society For Clinical Electrophysiology of Vision. ISCEV standard for clinical multifocal electroretinography (mfERG) (20II edition). Doc Ophthalmol 2012;124:1-13.

15. WHO. Global Report on Diabetes. Geneva: World Health Organization, 2016. Available at: http://apps.who.int/iris/bitstream/ handle/ I0665/20487 I/978924 I 565257_eng.pdf?sequence= I . Accessed Dec 10, 2018.

16. Ozawa GY, Bearse MA Jr, Adams AJ. Male-female differences in diabetic retinopathy? Curr Eye Res 2015;40:234-46.

17. Ozawa GY, Bearse MA Jr, Bronson-Castain KW, Harrison WW, Schneck ME, Barez S, et al. Neurodegenerative differences in the retinas of male and female patients with type 2 diabetes. Invest Ophthalmol Vis Sci 2012;53:3040-6.

18. Namperumalsamy P, Kim R, Vignesh TP, Nithya N, Royes J, Gijo $\mathrm{T}$, et al. Prevalence and risk factors for diabetic retinopathy: a population-based assessment from Theni District, south India. Br J Ophthalmol 2009;93:429-34.

19. Klein R, Klein BE, Moss SE, Davis MD, DeMets DL. The Wisconsin epidemiologic study of diabetic retinopathy. III. Prevalence and risk of diabetic retinopathy when age at diagnosis is 30 or more years. Arch Ophthalmol 1984;102:527-32.

20. Klein R, Klein BE, Moss SE, Cruickshanks KJ. The Wisconsin Epidemiologic Study of diabetic retinopathy. XIV. Ten-year incidence and progression of diabetic retinopathy. Arch Ophthalmol 1994;1 I2:1217-28.

21. Adhikari P, Marasini S, Sah RP, Joshi SN, Shrestha JK. Multifocal electroretinogram responses in Nepalese diabetic patients without retinopathy. Doc Ophthalmol 2014;129:39-46.

22. Han Y, Bearse MA Jr, Schneck ME, Barez S, Jacobsen CH, Adams AJ. Multifocal electroretinogram delays predict sites of subsequent diabetic retinopathy. Invest Ophthalmol Vis Sci 2004;45:948-54.

23. Dhamdhere KP, Bearse MA Jr, Harrison W, Barez S, Schneck ME, Adams AJ. Associations between local retinal thickness and function in early diabetes. Invest Ophthalmol Vis Sci 20I2;53:6I22-8.

24. Laron M, Bearse MA Jr, Bronson-Castain K, Jonasdottir S, KingHooper B, Barez S, et al. Association between local neuroretinal function and control of adolescent type I diabetes. Invest Ophthalmol Vis Sci 2012;53:707I-6.

25. Klemp K, Sander B, Brockhoff PB, Vaag A, Lund-Andersen $\mathrm{H}$, Larsen $M$. The multifocal ERG in diabetic patients without retinopathy during euglycemic clamping. Invest Ophthalmol Vis Sci 2005;46:2620-6. 